\title{
Diretrizes para implantação coletiva e semipresencial de sistemas certificáveis de gestão
}

\author{
Guidelines for the collective and semi-presence-based \\ implementation of certifiable management systems
}

\author{
Fábio Roberto Izeppe ${ }^{1}$ \\ Otávio José de Oliveira²
}

\begin{abstract}
Resumo: Este artigo tem por objetivo sistematizar diretrizes para implantação coletiva e semipresencial, situação em que não há participação ativa de um consultor ou especialista diretamente na empresa, de sistemas certificáveis de gestão, tais como a ISO 9001, ISO 14001 e OHSAS 18001. Este artigo é de cunho teórico-conceitual e, para seu desenvolvimento, foram estudadas mais diretamente quatro experiências práticas provenientes da teoria, de implantação coletiva e semipresencial de sistemas que, em conjunto com o referencial teórico geral, forneceram subsídios para a sistematização das diretrizes. Essas diretrizes estão estruturadas com base nos seguintes itens: seleção das empresas; sensibilização; diagnóstico; planejamento; treinamentos; implementação; verificação e correção.
\end{abstract}

Palavras-chave: Sistemas certificáveis de gestão. Implantação coletiva e semipresencial. ISO 9001. ISO 14001. OHSAS 18001.

\begin{abstract}
This paper aims to develop guidelines for the collective and semi-presence-based implementation of (a situation in which there is no active participation of a consultant specialist in the company) certifiable management systems. These systems include ISO 9001, ISO 14001, or OHSAS 18001. This is a theoretical and conceptual study which was based on four practical experiences of the theory of collective and semi-presence-based system implementation for the development of the guidelines proposed. These guidelines are drawn up according to the following items: selection of companies; awareness, diagnosis, planning, training, implementation, verification and improvement.

Keywords: Certifiable management systems. Collective and semi-presence-based implementation. ISO 9001. ISO 14001. OHSAS 18001.
\end{abstract}

\section{Introdução}

O cenário mercadológico, independente da área de atuação das organizações, está cada vez mais competitivo e com clientes mais exigentes. Nesse cenário, a adoção de sistemas certificáveis de gestão pode oferecer consideráveis vantagens competitivas (CHAN; WONG, 2006; SILVA FILHO et al., 2007; GAVRONSKI; FERRER; PAIVA, 2008).

Esses sistemas são constituídos de conjuntos de requisitos que auxiliam na execução de processos, objetivando o desenvolvimento de princípios específicos relacionados, por exemplo, com a gestão da qualidade (ISO 9001), gestão ambiental (ISO 14001) e saúde e segurança do trabalho (OHSAS 18001) (OLIVEIRA et al., 2011; BRANDLER; BRANDLI, 2011).
A existência de múltiplos sistemas certificáveis em uma empresa pode gerar diversos benefícios para as organizações, entre os quais se destacam o ganho sinérgico com a execução de tarefas padronizadas, redução dos custos de produção em função da minimização de desperdícios de materiais e energia, além de contribuir com a responsabilidade social e com o cumprimento da legislação. Esses fatores melhoram a imagem da empresa perante o mercado e a tornam mais competitiva (CHAN; WONG, 2006).

Para este artigo, se entende como semipresencial a implantação de sistemas certificáveis de gestão, em que não há participação ativa de um consultor ou especialista diretamente na empresa, uma vez que esta é realizada por meio de treinamentos e orientações em reuniões específicas, cujos conhecimentos são

\footnotetext{
${ }^{1}$ Departamento de Engenharia de Produção, Faculdade de Engenharia de Bauru, Universidade Estadual Paulista - UNESP, CEP 17033-360, Bauru, SP, Brasil, e-mail: fabioizeppe@terra.com.br

${ }^{2}$ Departamento de Produção, Faculdade de Engenharia de Guaratinguetá, Universidade Estadual Paulista - UNESP, CEP 12516-410, Guaratinguetá, SP, Brasil, e-mail: otaviodeoliveira@uol.com.br
}

Recebido em 19/9/2012 — Aceito em 26/4/2013

Suporte financeiro: Nenhum. 
posteriormente replicados por membros disseminadores dessas próprias empresas (OLIVEIRA, 2006).

Entende-se também que esses sistemas podem ser desenvolvidos de maneira coletiva, ou seja, realizados simultaneamente com um grupo de empresas, reduzindo-se consideravelmente seus custos e, portanto, possibilitando que maior número de empresas com menor capacidade financeira participe do programa (OLIVEIRA, 2006).

Dessa forma, fomenta-se a participação das pessoas, geram-se ganhos de diversas ordens e, por consequência, dotam-se as empresas de recursos mais eficazes para suplantarem seus concorrentes (CHAN; WONG, 2006; LO; YEUNG; CHENG, 2009).

A questão de pesquisa que norteou o desenvolvimento deste artigo foi a seguinte: de que forma pode se dar a implantação coletiva e semipresencial de sistemas certificáveis de gestão em empresas de forma a reduzir seus custos e maximizar seus resultados?

Com base no exposto, o objetivo deste artigo é sistematizar diretrizes para implantação coletiva e semipresencial de sistemas certificáveis de gestão, tais como a ISO 9001, ISO 14001 e OHSAS 18001.

Na sequência desta introdução, é apresentada uma síntese do referencial teórico: a análise das experiências que mais diretamente subsidiaram este trabalho; as diretrizes propriamente ditas; sua validação; a conclusão do estudo; e, por fim, as referências bibliográficas utilizadas.

\section{Síntese do referencial teórico}

A certificação de sistemas de gestão é o reconhecimento do atendimento dos requisitos relativos a esses padrões, que podem ser de qualidade, meio ambiente, segurança e saúde, etc. Ela é concedida por uma entidade certificadora credenciada por um órgão fiscalizador; papel realizado no Brasil pelo INMETRO (Instituto Nacional de Metrologia, Normalização e Qualidade Industrial), que é representante do organismo mundial International Organization for Standardization (GRAEL; OLIVEIRA, 2010; BRANDLER; BRANDLI, 2011).

Com foco na eficiência operacional e estruturada na forma de requisitos, as ideias, princípios e práticas da gestão da qualidade estão incorporados no sistema de gestão da qualidade com base na norma ISO 9001. Ela possui o objetivo de elevar a satisfação dos clientes por meio da capacidade de garantir que os produtos atendam a suas reais necessidades (TERZIOVSKI; POWER, 2007; LO; YEUNG; CHENG, 2009; MORIONES et al., 2011).

Com o objetivo de reduzir os impactos ambientais negativos e potencializar os positivos, o sistema de gestão ambiental baseado na norma ISO 14001 estabelece requisitos voltados às responsabilidades, práticas, procedimentos, políticas, avaliações, processos e recursos necessários para sua implantação. Um sistema de gestão ambiental faz com que um processo produtivo esteja em conformidade com uma política ambiental e possibilite a realização de processos sustentáveis, reduzindo custos a partir da melhor utilização dos recursos naturais e aplicação dos conceitos de produção mais limpa (BANSAL; BOGNER, 2002; CAMPOS; MELO, 2008; ARIMURA; HIBIKI; KATAYAMA, 2008).

A gestão da saúde e segurança do trabalho é uma forma sistemática de lidar proativamente com os desafios de reduzir riscos e problemas no ambiente de trabalho. Nesse contexto, a norma OHSAS 18001 (Occupational Health and Safety Assessment Standard) especifica os requisitos de um sistema de gestão da saúde e segurança do trabalho por meio de procedimentos, política, objetivos e metas, planejamento, identificação e monitoramento de perigos e riscos de acidentes e cumprimento dos requisitos legais (ZWETSLOOT et al., 2007; ROCHA, 2010; VINODKUMAR; BHASI, 2011).

Um dos principais elementos motivadores para a adoção dos sistemas certificáveis de gestão é a vantagem competitiva que eles geram, pois, de acordo com Oliveira, Oliveira e Almeida (2010), com a implantação e certificação de sistemas de gestão da qualidade, meio ambiente e segurança e saúde do trabalho, as organizações conquistam aumento da qualidade de produtos e serviços, desenvolvimento sustentável, melhor relacionamento com a sociedade e, consequentemente, aumentam sua lucratividade, podendo transformar as pressões de mercado em vantagens competitivas.

A certificação de sistemas oferece também benefícios que, além de fortalecer o cumprimento de obrigações legais, aumentam a transparência, melhoram a percepção da empresa sobre suas próprias forças e fraquezas, apoiam a análise e estruturas de custos e podem evidenciar seus aspectos positivos para seus clientes (KIRSCH et al., 2010).

Os elementos impulsionadores da adoção e certificação desses sistemas podem ser agrupados em duas categorias: internas e externas (SINGH; POWER; CHUONG, 2011).

Os estudos focados nos elementos internos têm como premissa que a implantação de um sistema certificável de gestão auxilia as organizações a melhorar processos internos, aumentando seu desempenho geral (SINGH; POWER; CHUONG, 2011). Externamente, Clougherty e Grajek (2008) afirmam que algumas organizações certificam-se para atender às expectativas do mercado e melhorar a conformidade com os requisitos regulamentares e as exigências governamentais.

Além disso, algumas organizações usam os padrões normativos para afirmar e/ou potencializar o status que possuem no mercado. Contudo, organizações 
motivadas puramente por razões externas tendem a adotar níveis mínimos de padrões de excelência nos seus processos e práticas internas. Como consequência, melhorias significativas no desempenho interno são menos prováveis de serem conseguidas (TERLAAK; KING, 2006).

A adoção destas normas implica necessariamente no mapeamento de processos e em muitos casos mudanças significativas neles. Há, portanto, implicações para os processos internos mesmo que a motivação seja puramente de origem externa (SINGH; POWER; CHUONG, 2011).

Pesquisas apontam recorrentes dificuldades na implantação de sistemas certificáveis de gestão, como imprecisão na definição de objetivos e metas, resistência a mudanças, entre outras. Entre as principais dificuldades encontradas durante a implantação, a resistência à mudança é uma das mais significativas. Esse fato pode estar relacionado com o alto índice de utilização de consultorias especializadas para implantação do sistema ISO 9001 e com a baixa utilização de times da qualidade, ou seja, a adoção de equipes internas durante a implantação é um fator que reduz a resistência à mudança (OLIVEIRA et al., 2011).

De acordo com Pinto, Carvalho e Ho (2006), em uma pesquisa sobre a implantação de sistemas de gestão em 198 empresas de grande porte no Brasil, $60,4 \%$ delas apontaram como a principal dificuldade a baixa disponibilidade de recursos.

A implantação de um sistema de gestão da qualidade antes dos demais, a utilização de programas e ferramentas da qualidade, a participação direta dos funcionários na elaboração da política e objetivos, o incentivo (reconhecimento e premiação) de ideias, a sensibilização dos funcionários e o desenvolvimento de lideranças facilitam a superação das principais dificuldades (OLIVEIRA; PINHEIRO, 2010; PSOMAS et al., 2011; OLIVEIRA et al., 2011).

A produção de produtos e serviços com qualidade, respeitando as pessoas e o meio ambiente, não é uma tarefa fácil de ser conseguida. Para a implantação de qualquer novo projeto dentro desse contexto, é necessário considerar o "fator organização", o que inclui as coordenadas humanas, culturais e suas limitações (BOUYER; CAMPOS; PONCIANO, 2006).

A implantação de sistemas certificáveis de gestão exige o planejamento, execução de avaliações sistemáticas e constantes treinamentos, o que eleva o capital intelectual - importante elemento para amenizar a resistência às mudanças (RONDINELLI; VASTAG, 2000).

Para o desenvolvimento e a implantação de um sistema certificável de gestão é necessário garantir o comprometimento de todos com o objetivo de conquistar a excelência, possibilitando o aprimoramento contínuo. A área de recursos humanos
(RH) tem como fim a utilização das pessoas para o alcance dos objetivos empresariais, reconhecendo-se que a qualidade dessa gestão influencia diretamente a capacidade da organização e de seus empregados em levar a cabo suas incumbências, incluindo-se o auxílio durante a implantação de um sistema certificável de gestão (MILKOVICH; BOUDREAU, 2000).

O treinamento técnico para funcionários do chão de fábrica e o envolvimento da direção em todo o processo são também fatores importantes para o desenvolvimento e a manutenção dos sistemas de gestão. Os funcionários se tornam mais dispostos a cooperar com os projetos propostos pela organização quando começam a acreditar no real comprometimento da direção, proporcionando o sentimento de responsabilidade coletiva, tornando-se um fator decisivo para o sucesso da mudança (LANGFORD; ROWLINSON; SAWACHA, 2000; CHOUDHRY; FANG; MOHAMED, 2007; SHI et al., 2008; WAHID; CORNER; TAN, 2011).

\section{Método de pesquisa}

Este artigo é de cunho teórico-conceitual, ou seja, as diretrizes, que foram validadas por especialistas, são decorrentes de uma revisão teórica em conjunto com uma análise mais detalhada de quatro experiências específicas relacionadas com implantação conjunta e semipresencial de sistemas certificáveis de gestão (NORONHA; FERREIRA, 2000). Ele objetiva sintetizar diretrizes e identificar algumas possibilidades de pesquisas futuras.

Com base no critério de utilizar apenas experiências publicadas como artigos científicos, teses ou dissertações, facilidade de acesso/consulta aos autores e situações semelhantes à estudada neste trabalho, foram selecionadas quatro experiências de implantação coletiva e semipresencial de sistemas certificáveis de gestão conforme descritas a seguir:

- a) modelo de padronização de processos produtivos em panificadoras do Programa de Apoio à Panificação (TEIXEIRA, 2010);

- b) programa de implantação coletiva de sistema de gestão da qualidade ISO 9001 do SEBRAE - Bauru (OLIVEIRA, 2010);

- c) implantação coletiva de sistema de gestão da qualidade com base na norma ISO 9001 em empresas de Bauru do SENAI/CIESP (RISSATTO, 2008); e

- d) implantação de modelo de gestão para pequenas empresas de projeto de edifícios do Programa de Construção Civil da Escola Politécnica da USP (OLIVEIRA, 2006).

A análise dessas experiências foi guiada pela identificação das características dos seguintes itens: seleção das empresas; sensibilização; diagnóstico; 
planejamento; treinamentos; implementação; verificação; correção, resultados e dificuldades.

$\mathrm{O}$ desenvolvimento desta pesquisa foi baseado em 6 elementos principais, que incluem a introdução (questão de pesquisa e objetivo), síntese do referencial teórico, análise das experiências, diretrizes, validação e conclusão. A Figura 1 apresenta a estrutura metodológica do desenvolvimento desse artigo.

\section{Análise das experiências de implan- tação coletiva e semipresencial}

As experiências que foram objeto desta análise serviram de base para a sistematização das diretrizes para implementação conjunta e semipresencial de sistemas certificáveis de gestão apresentadas na próxima seção. O Quadro 1 apresenta o resumo da análise dessas experiências.

As experiências com melhores resultados foram aquelas em que havia um processo de seleção bem estabelecido das empresas participantes. Ficou evidenciado que empresas participantes que não possuem os processos básicos necessários para seu próprio gerenciamento podem prejudicar o andamento e sucesso do projeto.

Nas experiências em que houve um forte envolvimento da direção, os resultados obtidos foram superiores, sendo esta uma das principais variáveis para o sucesso dos projetos de implantação coletiva de sistemas certificáveis de gestão. Ficou evidenciado pelas experiências e pelo referencial teórico que a falta de envolvimento da direção e a insuficiente disponibilização de recursos prejudicam consideravelmente o desempenho do projeto de implantação.

O levantamento de necessidades de investimentos, quando bem realizado, facilita a tomada de decisão da direção e aumenta a disponibilidade de capital e demais recursos para projeto. O planejamento realizado desde o início, baseado em um diagnóstico, ofereceu melhores resultados do que as implantações que não dispuseram grande atenção a esse processo.

O treinamento é um fator crítico identificado pelo referencial teórico e evidenciado nas experiências. Sua execução por completo, no início do projeto, não é recomendável, como comprovado pelas experiências analisadas. Eles devem ser diluídos ao longo da implantação. Alguns conceitos aplicados no início podem não ser lembrados no final do projeto, havendo necessidade de revisão contínua desses conceitos.

Os projetos, cuja verificação foi realizada junto com a execução da próxima etapa de implantação, obtiveram resultados inferiores. Foi verificado que não havia tempo hábil de correção, principalmente se fossem etapas interdependentes. O ideal é que houvesse mais tempo para sua realização, mas isso pode atrasar consideravelmente o projeto.

Os projetos, em que não foi previsto tempo específico para a execução das correções, tiveram atrasos no cronograma de implantação. A falta de ferramentas para verificação e correção também prejudicaram o gerenciamento das adequações necessárias.

\section{Diretrizes para implantação coleti- va e semipresencial de sistemas certificáveis de gestão}

As diretrizes estão agrupadas em quatro macroitens: planejamento, execução, verificação e correção. No primeiro, serão apresentadas as diretrizes referentes à seleção das empresas, diagnóstico e planejamento do projeto de implantação coletiva semipresencial de sistemas certificáveis de gestão. O segundo

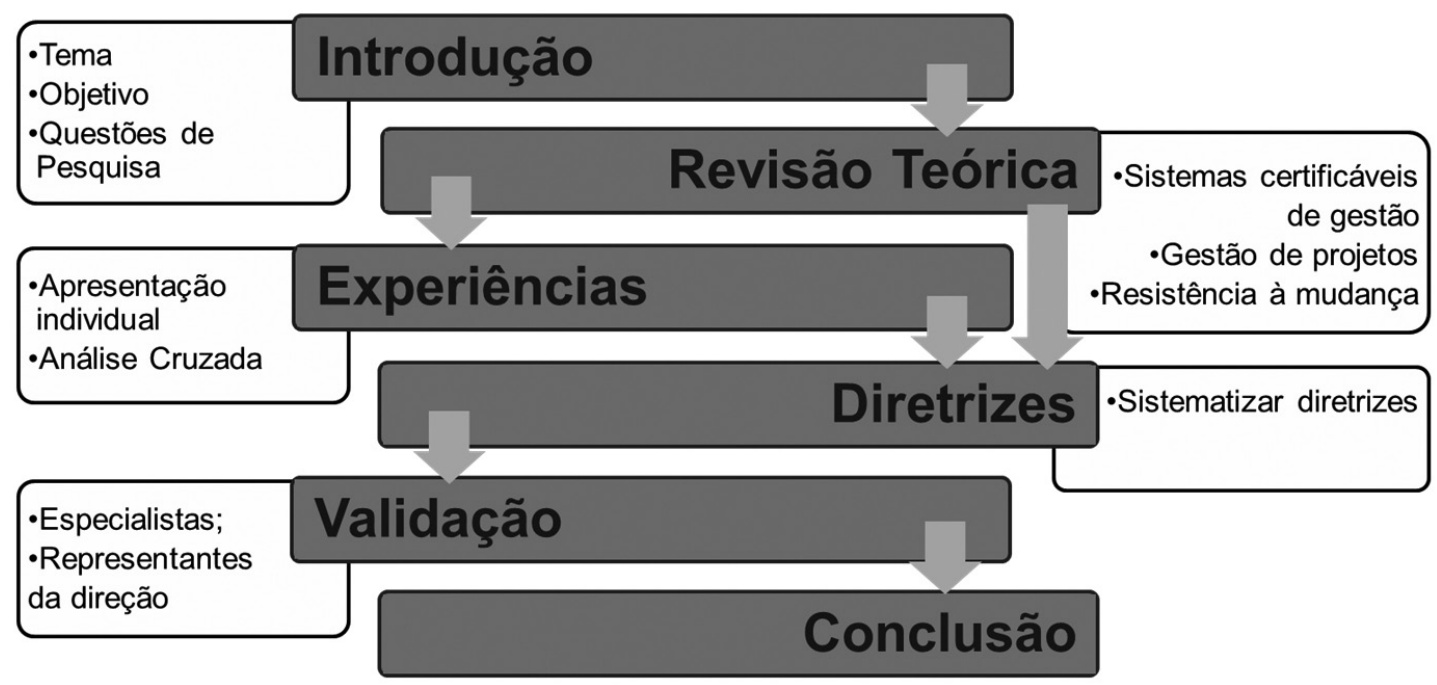

Figura 1. Estrutura metodológica do desenvolvimento do artigo. 
Quadro 1. Apresentação e análise resumida das experiências.

\begin{tabular}{|c|c|c|c|c|}
\hline & Panificadoras & SEBRAE & SENAI & Projetos \\
\hline Seleção & $\begin{array}{l}\text { Não foi utilizado um } \\
\text { método específico para } \\
\text { seleção das empresas. }\end{array}$ & $\begin{array}{l}\text { Realizada por meio } \\
\text { de um questionário } \\
\text { de autoavaliação e } \\
\text { diagnóstico feito por } \\
\text { um consultor. }\end{array}$ & $\begin{array}{l}\text { Não foi utilizado um } \\
\text { método específico } \\
\text { para seleção das } \\
\text { empresas. }\end{array}$ & $\begin{array}{l}\text { Selecionada pela } \\
\text { área de atuação e } \\
\text { localização. }\end{array}$ \\
\hline Diagnóstico & $\begin{array}{l}\text { Não houve diagnóstico } \\
\text { das empresas } \\
\text { participantes. }\end{array}$ & $\begin{array}{l}\text { Realizado durante a } \\
\text { seleção das empresas, } \\
\text { sem alterações no } \\
\text { planejamento nem na } \\
\text { implementação. }\end{array}$ & $\begin{array}{l}\text { Realizado e utilizado } \\
\text { para adaptar e } \\
\text { adequar a etapa } \\
\text { de planejamento e } \\
\text { implementação. }\end{array}$ & $\begin{array}{l}\text { Na primeira metade } \\
\text { das empresas, foi } \\
\text { realizado diagnóstico } \\
\text { no início. Na segunda } \\
\text { metade das empresas } \\
\text { participantes, foi } \\
\text { realizado por um } \\
\text { questionário antes de } \\
\text { cada etapa. }\end{array}$ \\
\hline Planejamento & $\begin{array}{l}\text { Sem planejamento } \\
\text { rigidamente definido, } \\
\text { apenas um método a ser } \\
\text { aplicado em } 4 \text { etapas. }\end{array}$ & $\begin{array}{l}\text { Pré-definido no } \\
\text { método utilizado. }\end{array}$ & $\begin{array}{l}\text { Elaborados de acordo } \\
\text { com a necessidade e } \\
\text { o diagnóstico de cada } \\
\text { empresa. }\end{array}$ & $\begin{array}{l}\text { Definido no início do } \\
\text { projeto em conjunto } \\
\text { com as empresas, } \\
\text { seguindo o método } \\
\text { definido. }\end{array}$ \\
\hline Sensibilização & $\begin{array}{l}\text { Não houve uma } \\
\text { etapa específica de } \\
\text { sensibilização da } \\
\text { direção. }\end{array}$ & $\begin{array}{l}\text { Realizado um } \\
\text { seminário no início } \\
\text { do projeto, no qual } \\
\text { foi apresentado } \\
\text { o cronograma e } \\
\text { requisitos, incluindo } \\
\text { necessidades de } \\
\text { recursos para a } \\
\text { implantação. }\end{array}$ & $\begin{array}{l}\text { Palestra de } 4 \text { horas } \\
\text { para apresentar o } \\
\text { escopo do projeto aos } \\
\text { diretores. }\end{array}$ & $\begin{array}{l}\text { Realizadas durante } \\
\text { a definição do } \\
\text { planejamento e } \\
\text { reuniões mensais de } \\
\text { implementação. }\end{array}$ \\
\hline Treinamentos & $\begin{array}{l}\text { Executados durante a } \\
\text { implementação de cada } \\
\text { etapa. }\end{array}$ & $\begin{array}{l}\text { Realizados antes da } \\
\text { implementação. }\end{array}$ & $\begin{array}{l}\text { Realizados durante } \\
\text { a implementação de } \\
\text { cada etapa. }\end{array}$ & $\begin{array}{l}\text { Executados durante } \\
\text { as reuniões de } \\
\text { implementação. }\end{array}$ \\
\hline Implementação & $\begin{array}{l}\text { Para cada etapa de } \\
\text { implantação é executado } \\
\text { um treinamento, que } \\
\text { os responsáveis pela } \\
\text { implementação deverão } \\
\text { aplicar na prática. }\end{array}$ & $\begin{array}{l}\text { Realizada por meio } \\
\text { de consultoria com } \\
\text { visitas quinzenais, nas } \\
\text { quais eram verificados } \\
\text { todos os conceitos } \\
\text { e ferramentas dos } \\
\text { treinamentos. }\end{array}$ & $\begin{array}{l}\text { Realizada por meios } \\
\text { de treinamentos e } \\
\text { consultoria para cada } \\
\text { etapa. }\end{array}$ & $\begin{array}{l}\text { Reuniões mensais } \\
\text { com estabelecimento } \\
\text { de atividades e metas. }\end{array}$ \\
\hline Verificação & $\begin{array}{l}\text { Realizada antes da } \\
\text { execução da próxima } \\
\text { etapa, ambos na mesma } \\
\text { ocasião. }\end{array}$ & $\begin{array}{l}\text { Na metade do projeto, } \\
\text { foi executada a } \\
\text { primeira auditoria; a } \\
\text { segunda foi realizada } \\
\text { no final do projeto. }\end{array}$ & $\begin{array}{l}\text { Realizada por meio de } \\
\text { uma auditoria no final } \\
\text { da implementação. }\end{array}$ & $\begin{array}{l}\text { Eram realizadas } \\
\text { visitas para sanar } \\
\text { dúvidas e monitorar o } \\
\text { desenvolvimento do } \\
\text { projeto. }\end{array}$ \\
\hline Correção & $\begin{array}{l}\text { Não foi disponibilizada } \\
\text { uma etapa específica para } \\
\text { correção de problemas na } \\
\text { implantação. }\end{array}$ & $\begin{array}{l}\text { Execução de ações } \\
\text { corretivas antes da } \\
\text { certificação. }\end{array}$ & $\begin{array}{l}\text { Execução de ações } \\
\text { corretivas antes da } \\
\text { certificação. }\end{array}$ & $\begin{array}{l}\text { Correção efetuada } \\
\text { após as verificações } \\
\text { realizadas in loco. }\end{array}$ \\
\hline Resultados & $\begin{array}{l}\text { Nem todas as empresas } \\
\text { obtiveram sucesso, as } \\
\text { mais preparadas antes } \\
\text { do projeto obtiveram } \\
\text { resultados melhores que } \\
\text { as menos preparadas. }\end{array}$ & $\begin{array}{l}\text { Empresas certificadas } \\
\text { com atraso no } \\
\text { cronograma devido a } \\
\text { interrupção e execução } \\
\text { de treinamentos } \\
\text { e consultoria em } \\
\text { momentos diferentes. }\end{array}$ & $\begin{array}{l}\text { Empresas certificadas, } \\
\text { mas com dificuldades } \\
\text { com relação à } \\
\text { disponibilização de } \\
\text { recursos, incluindo } \\
\text { investimentos e dispo- } \\
\text { nibilidade de pessoal. }\end{array}$ & $\begin{array}{l}\text { Implementação de } \\
\text { um modelo de gestão } \\
\text { e verificação de } \\
\text { mudanças positivas } \\
\text { no comportamento da } \\
\text { direção. }\end{array}$ \\
\hline Dificuldades & $\begin{array}{l}\text { Falta de envolvimento } \\
\text { da direção no projeto } \\
\text { e empresas com níveis } \\
\text { gerenciais diferentes } \\
\text { pela falta de um critério } \\
\text { de seleção bem-definido. }\end{array}$ & $\begin{array}{l}\text { Método adotado } \\
\text { para aplicação } \\
\text { dos treinamentos } \\
\text { dificultou o projeto de } \\
\text { implantação. }\end{array}$ & $\begin{array}{l}\text { Falta de um plano } \\
\text { de investimentos } \\
\text { ou métodos para } \\
\text { identificação de } \\
\text { necessidades de } \\
\text { recursos. } \\
\end{array}$ & $\begin{array}{l}\text { Não houve } \\
\text { dificuldades } \\
\text { consideráveis por } \\
\text { tratar-se de um } \\
\text { projeto de preparação. }\end{array}$ \\
\hline
\end{tabular}


apresenta os elementos da execução da implantação coletiva e semipresencial, incluindo a sensibilização da direção da empresa, treinamentos e execução da implantação. O terceiro e quarto macroitem correspondem respectivamente à verificação e às ações de correção. Sua estrutura foi pensada a partir do ciclo PDCA (plan, do, check e act), conforme a Figura 2.

\subsection{Seleção das empresas}

Empresas que já possuem uma boa base de gestão tendem a ter melhor resultado no projeto de implantação de sistemas certificáveis de gestão. É desejável, porém não obrigatório, que as empresas participantes tenham o mínimo desenvolvimento nos seguintes elementos: sistema de informações; controle de custos e estrutura de produtos; gestão de recursos humanos; gestão comercial; gestão de compras; gestão de estoques; gestão de projetos; gestão da produção e atendimento de legislação relacionada ao sistema certificável de gestão a ser implantado.

As empresas deverão se comprometer a disponibilizar um coordenador para o projeto de implantação. Ele participará ativamente das atividades de implantação e coordenará os demais participantes da sua empresa.

Cada sistema certificável de gestão determina o atendimento de legislações específicas. O sistema de gestão da qualidade ISO 9001 determina a necessidade de atendimento de legislações relacionadas ao produto; o sistema de gestão ambiental ISO 14001 determina a necessidade de atendimento e avaliação das legislações ambientais; e o sistema de saúde e segurança ocupacional OHSAS 18001 determina a necessidade do atendimento de legislações da saúde e segurança do trabalhador. É desejável que as empresas conheçam essas legislações e as atendam.

Para um projeto de implantação de um sistema certificável de gestão da qualidade, por exemplo, há portarias específicas relacionadas a produtos que

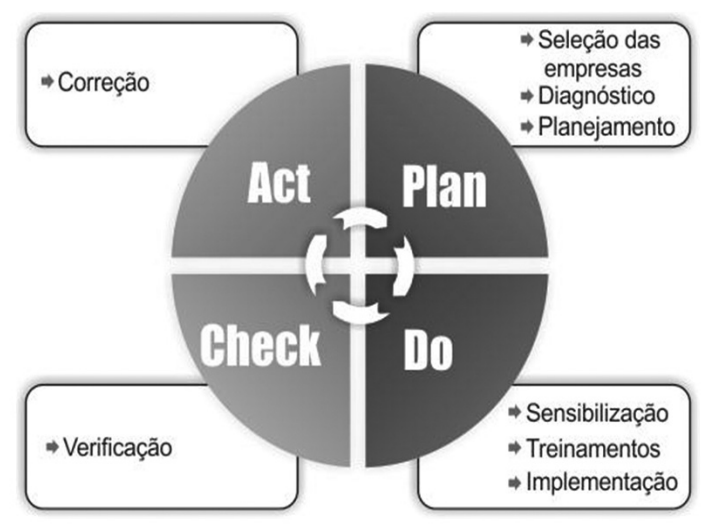

Figura 2. Estrutura das diretrizes. determinam a necessidade de certificação compulsória ou legislações como as da Agencia Nacional da Vigilância Sanitária, que determinam a necessidade de boas práticas de fabricação para indústrias alimentícias, farmacêuticas e de cosméticos. A mesma verificação deve ser realizada para os sistemas de gestão ambiental e saúde e segurança ocupacional.

Quanto maior for o número de processos a serem implementados e legislações a serem atendidas, maior será o tempo necessário para a implantação de um sistema certificável de gestão. Portanto, dependendo do planejamento do projeto, será inviável a participação de empresas que não possuem algum desses processos implementados ou legislações atendidas. Estas verificações podem ser agrupadas em um formulário de entrevistas para auxiliar a seleção das empresas.

\subsection{Diagnóstico}

Com as empresas selecionadas, faz-se necessária a realização de um diagnóstico técnico, relacionando os requisitos do sistema de gestão a serem implementados com a situação atual da empresa.

Em conjunto com a execução do diagnóstico, deve ser efetuado o levantamento das principais necessidades de investimentos. Para a realização do diagnóstico, pode ser utilizado um quadro que expõe os requisitos do sistema certificável de gestão a ser implantado e as empresas selecionadas. Nesse quadro, devem ser expostas notas para o atendimento de cada requisito (ver exemplo no Quadro 2).

Pode ser executado o cálculo da média do atendimento de cada requisito para o dimensionamento da etapa de planejamento.

\subsection{Planejamento}

Para o planejamento, é recomendada a utilização da ferramenta Gráfico de Gantt, em que deverão ser definidas todas as etapas com seus respectivos prazos e atividades. Os tópicos do planejamento podem se basear nos requisitos do sistema certificável de gestão a ser implantado.

A ferramenta de diagnóstico fornece informações para a realização e elaboração do planejamento. Devem ser considerados requisitos que possuem média de atendimento baixa para dimensionar mais tempo para seus treinamentos e implantação. Esta regra deve ser aplicada de forma inversa aos requisitos que possuem uma média de atendimento superior.

O planejamento deve conter a sequência de atividades, prazos e responsáveis pela sua execução. O Quadro 3 apresenta a utilização do gráfico de Gantt para o planejamento, no qual há a definição dos responsáveis e prazos para a implantação de um sistema certificável de gestão ambiental. 
Quadro 2. Proposta de instrumento para diagnóstico.

\begin{tabular}{|l|l|c|c|c|c|}
\hline Req. & \multicolumn{1}{|c|}{ Descrição } & Empresa 1 & Empresa 2 & Empresa N & Média \\
\hline 4.1 & Requisitos Gerais & 1 & 0 & 0 & $33 \%$ \\
\hline 4.2 .1 & Requisitos de documentação & 0 & 1 & 1 & $66 \%$ \\
\hline 4.2 .2 & Manual da Qualidade & 1 & 1 & 1 & $100 \%$ \\
\hline $\mathrm{n}$ & $\ldots$ & $\ldots$ & $\ldots$ & $\ldots$ & $\ldots$ \\
\hline
\end{tabular}

Quadro 3. Proposta de instrumento para planejamento.

\begin{tabular}{|c|c|c|c|c|c|c|c|c|c|c|c|c|c|c|}
\hline \multicolumn{3}{|c|}{ Meses e Semanas } & \multicolumn{4}{|c|}{ Abril } & \multicolumn{4}{|c|}{ Maio } & \multicolumn{4}{|c|}{ Junho } \\
\hline Req. & Descrição & Responsável & 1 & 2 & 3 & 4 & 1 & 2 & 3 & 4 & 1 & 2 & 3 & 4 \\
\hline- & Encontro 01 & - & & & & & & & & & & & & \\
\hline 4.1 & Requisitos Gerais & João & & & & & & & & & & & & \\
\hline 4.2 & Política Ambiental & João & & & & & & & & & & & & \\
\hline 4.3 .1 & Aspectos e Impactos & Pedro & & & & & & & & & & & & \\
\hline- & Encontro 02 & - & & & & & & & & & & & & \\
\hline 4.3 .2 & Requisitos Legais e Outros & João & & & & & & & & & & & & \\
\hline 4.3 .4 & Objetivos Metas e Programas & Pedro & & & & & & & & & & & & \\
\hline- & Encontro X & - & & & & & & & & & & & & \\
\hline $\mathrm{n}$ & $\ldots$ & $\ldots$ & & & & & & & & & & & & \\
\hline
\end{tabular}

O planejamento deve conter a previsão dos encontros, nos quais serão realizados os respectivos treinamentos sobre os conceitos e ferramentas relativos ao sistema certificável de gestão a ser implementado. As auditorias internas e de certificação também devem ser estabelecidas nesse cronograma, bem como a análise crítica do sistema de gestão.

\subsection{Sensibilização}

Recomenda-se a realização de um evento envolvendo todos os membros para apresentação do projeto.

Nesse evento devem ser abordados os seguintes tópicos:

- vantagens da implementação do sistema certificável de gestão e explicitação dos resultados que podem ser alcançados;

- o cronograma de implantação com os prazos e responsáveis;

- apresentação simplificada dos requisitos do sistema certificável de gestão a ser implantado; e

- reforço da necessidade do comprometimento de todos os envolvidos no projeto com os prazos e atividades a serem desenvolvidas ao longo de sua execução.

É importante salientar a necessidade da disponibilização de recursos para possíveis adequações físicas, treinamentos, auditorias, atendimento a legislações, entre outras necessidades. Sensibilizações internas com os funcionários também devem ser realizadas com o objetivo de seu envolvimento no processo de implantação. O Representante da Direção (RD) deve coordenar estas atividades.

Devem ser incluídas no cronograma de implantação as reuniões periódicas com a direção com objetivo de analisar o andamento do projeto e, se necessário, ajustá-lo. Nestas reuniões, é recomendável a apresentação de relatórios padronizados sobre o detalhamento das atividades executadas e a situação atual do cronograma de implantação.

\subsection{Treinamentos}

Faz-se necessária a realização de treinamento para cada etapa antes de sua implementação. Devem ser abordados os principais conceitos, os métodos de implantação a serem utilizados e as técnicas para sua disseminação. No primeiro encontro deve ser realizado um treinamento simplificado sobre os requisitos a serem implantados para facilitar o entendimento geral dos participantes.

As atividades em grupo favorecem o envolvimento das pessoas e, em conjunto com o material de apoio, auxiliam a implantação semipresencial, pois eventuais consultas e dúvidas podem ser esclarecidas pelo material. Pode-se disponibilizar algum canal de comunicação de suporte, como e-mail, site, telefone, etc., para auxiliar nesse processo.

Devem ser previstos treinamentos sobre liderança, ferramentas da qualidade e auditorias. $\mathrm{O}$ treinamento sobre liderança deve ser executado no início do projeto, pois ele favorece a introdução dos conceitos e requisitos relativos ao sistema certificável de gestão dentro da organização. 
O treinamento sobre ferramentas da qualidade fornece o conteúdo teórico necessário para utilização e aplicação de instrumentos que auxiliem a implantação dos sistemas certificáveis de gestão. Ferramentas como $5 \mathrm{~W} 1 \mathrm{H}$, brainstorming, diagrama de Ishikawa, Controle Estatístico de Processo (CEP), entre outras facilitam o monitoramento de processos e o gerenciamento de ações corretivas e preventivas.

Antes da realização da auditoria interna, recomenda-se a execução de um treinamento de formação de auditores internos do sistema certificável de gestão a ser implantado. Esse treinamento formará as pessoas que executarão a auditoria interna, que será tratada na etapa de verificação destas diretrizes.

\subsection{Implementação}

A implantação conjunta e a semipresencial devem ser realizadas por meio de encontros de acordo com as datas planejadas no cronograma do projeto. Em cada encontro, devem ser apresentados os requisitos que serão implantados durante o próximo período. Deve ser efetuada a leitura e interpretação de cada requisito e realizados debates sobre como podem ser desenvolvidos.

Podem ser executadas pequenas simulações do atendimento dos requisitos pelas empresas. No encontro, devem ser expostos os objetivos parciais e as tarefas a serem desenvolvidos e alcançados no período. É recomendada a definição de responsáveis e prazos para a execução e seu atendimento. Isto pode ser feito por meio da ferramenta $5 \mathrm{~W} 1 \mathrm{H}$, conforme sugere o Quadro 4.

É necessária a preparação dos agentes multiplicadores para cada etapa da implantação. Para isso devem ser apresentados métodos sobre como devem envolver os demais colaboradores para auxiliar os agentes.

\subsection{Verificação}

É recomendada a realização de uma verificação do desempenho da etapa anterior antes do início de cada próxima etapa, assim a empresa poderá executar as ações necessárias para sua adequação ou correção.

Ela poderá ser executada pela empresa com seus recursos humanos próprios ou em conjunto com os consultores de implantação, visando analisar o plano de ação proposto de acordo com o Quadro 4. Esta reunião pode ser realizada por meios eletrônicos ou de forma presencial. Nela deve-se discutir as dificuldades encontradas e gerar alternativas para eventuais ajustes a serem realizados tanto no método como nos prazos. Deve-se também verificar o cumprimento do cronograma e o cumprimento dos requisitos do sistema que está sendo implantado e os motivos para os desvios.

Antes da auditoria de certificação, deve ser realizada uma auditoria interna, que verifique todos os processos e instalações pertinentes. Esta deve ser inserida no planejamento e deve contemplar todos os requisitos do sistema certificável de gestão.

Tanto a verificação da etapa anterior como a auditoria interna podem ser realizadas com o auxílio de uma lista de verificação de cada item, conforme apresentado no Quadro 5.

\subsection{Correção}

Depois da verificação, é necessário gerar soluções para os principais problemas de implantação e gerenciar

Quadro 4. Proposta de instrumento para gerenciamento de tarefas e objetivos parciais.

\begin{tabular}{|l|c|l|c|c|c|}
\hline \multicolumn{1}{|c|}{ O Que? } & Quem? & \multicolumn{1}{c|}{ Como? } & Quando? & Onde? & Quanto? \\
\hline $\begin{array}{l}\text { Elaboração da planilha } \\
\text { de aspectos e impactos }\end{array}$ & João & $\begin{array}{l}\text { Com software } \\
\text { específico }\end{array}$ & Até 10/6 & Na própria empresa & R $\$ 0$ \\
\hline $\begin{array}{l}\text { Levantamento dos } \\
\text { aspectos e impactos }\end{array}$ & João e Pedro & $\begin{array}{l}\text { Em conjunto } \\
\text { com a equipe }\end{array}$ & Até 30/6 & Na própria empresa & $\mathrm{R} \$ 0$ \\
\hline $\begin{array}{l}\text { Levantamento de } \\
\text { legislações ambientais }\end{array}$ & Pedro & $\begin{array}{l}\text { Contratação } \\
\text { de empresa } \\
\text { especializada }\end{array}$ & Até 22/6 & Na própria empresa & $\mathrm{R} \$ 500,00$ \\
\hline
\end{tabular}

Quadro 5. Proposta de instrumento para lista de verificação de requisitos.

\begin{tabular}{|l|c|c|c|c|}
\hline Req. & Descrição & Conforme & Não conforme & \multicolumn{1}{c|}{ Comentário } \\
\hline 4.1 & Requisitos Gerais & $\mathrm{X}$ & $\mathrm{X}$ & $\begin{array}{l}\text { Não foi possível evidenciar a implantação } \\
\text { da política ambiental }\end{array}$ \\
\hline 4.2 & Política Ambiental & & $\mathrm{X}$ & $\begin{array}{l}\text { Requisitos atendidos por meio da planilha } \\
\text { de aspectos e impactos ambientais }\end{array}$ \\
\hline 4.3 .1 & Aspectos e Impactos & \multicolumn{2}{|c}{} \\
\hline
\end{tabular}


as correções e adequações para preparar a empresa para as próximas etapas, e assim sucessivamente até a certificação do sistema de gestão.

É importante a utilização das ferramentas da qualidade para definição de ações, prazos e responsáveis para as correções. Essas ações deverão ser gerenciadas pelo coordenador do projeto de implantação, com o objetivo de garantir que sejam concluídas antes do início da próxima etapa.

Para cada não conformidade apontada, tanto na verificação como na auditoria interna, é recomendável o seu tratamento como ação corretiva, o que significa a análise de causa, definição dos planos de ação e verificação da eficácia das ações.

Para a análise das causas, podem ser utilizadas as ferramentas da qualidade como 5 porquês ou ainda o diagrama de Ishikawa. O objetivo é definir a causa real do problema na implantação para que ele não volte a ocorrer, o que vai caracterizar a ação preventiva.

Para a definição dos planos de ação, pode ser utilizada a ferramenta $5 \mathrm{~W} 1 \mathrm{H}$, já exemplificada no item de implantação destas diretrizes com o Quadro 4. Com ela é possível estabelecer os prazos e os responsáveis por ação corretiva.

\section{Validação}

Com o intuito de elevar seu grau de aplicabilidade, as diretrizes propostas foram encaminhadas a especialistas em implantação de sistemas certificáveis de gestão para críticas e sugestões de melhorias.

O primeiro especialista é um consultor, Mestre em Transportes, com quinze anos de experiência na implantação e manutenção de sistemas certificáveis de gestão. O segundo especialista é Mestre em Engenharia de Produção e professor de disciplinas relacionadas com sistemas certificáveis de gestão. $\mathrm{O}$ terceiro é RD de uma grande empresa do segmento de fertilizantes, especialista em Engenharia de Produção e já participou da implantação de sistemas certificáveis de gestão em outras empresas. As principais recomendações e comentários dos três especialistas são apresentados no

Quadro 6. Recomendações e comentários dos especialistas.

\begin{tabular}{|c|c|c|c|}
\hline & Consultor & Professor & RD \\
\hline Seleção & $\begin{array}{l}\text { O atendimento à legislação } \\
\text { referente ao sistema de gestão } \\
\text { precisa ser um item de sua } \\
\text { exclusão do programa. }\end{array}$ & $\begin{array}{l}\text { Recomenda a elaboração de } \\
\text { um formulário para entrevista } \\
\text { em relação ao sistema de } \\
\text { gestão. }\end{array}$ & $\begin{array}{l}\text { Recomenda que a empresa } \\
\text { possua um coordenador que } \\
\text { trabalhará exclusivamente } \\
\text { com o projeto de certificação. }\end{array}$ \\
\hline Diagnóstico & $\begin{array}{l}\text { Recomenda o desmembramento } \\
\text { do modelo de diagnóstico por } \\
\text { fases. }\end{array}$ & $\begin{array}{l}\text { Recomenda a utilização do } \\
\text { formulário de diagnóstico para } \\
\text { a seleção das empresas. }\end{array}$ & $\begin{array}{l}\text { Não foram descritas } \\
\text { recomendações. }\end{array}$ \\
\hline Planejamento & $\begin{array}{l}\text { Recomenda a inserção no } \\
\text { cronograma da análise crítica do } \\
\text { sistema certificável de gestão. }\end{array}$ & $\begin{array}{l}\text { Recomenda a inserção dos } \\
\text { requisitos da norma em um } \\
\text { check list. }\end{array}$ & $\begin{array}{l}\text { Não foram descritas } \\
\text { recomendações. }\end{array}$ \\
\hline Sensibilização & $\begin{array}{l}\text { Recomenda a realização de uma } \\
\text { apresentação simplificada dos } \\
\text { requisitos do sistema certificável } \\
\text { de gestão a ser implantado. }\end{array}$ & $\begin{array}{l}\text { Recomenda a definição de } \\
\text { padrões para otimizar os } \\
\text { encontros com a direção das } \\
\text { empresas participantes. }\end{array}$ & $\begin{array}{l}\text { Recomenda que a direção } \\
\text { realize uma sensibilização } \\
\text { com os funcionários para } \\
\text { o lançamento do projeto } \\
\text { internamente. }\end{array}$ \\
\hline Treinamentos & $\begin{array}{l}\text { No primeiro encontro, deve-se } \\
\text { apresentar simplificadamente } \\
\text { os requisitos das normas para } \\
\text { facilitar o entendimento da } \\
\text { relação entre eles e o que se terá } \\
\text { pela frente. }\end{array}$ & $\begin{array}{l}\text { Recomenda a disponibilização } \\
\text { dos materiais de apoio uma } \\
\text { semana antes, com o objetivo } \\
\text { de realizar uma introdução } \\
\text { teórica sobre o tema antes do } \\
\text { próximo encontro. }\end{array}$ & $\begin{array}{l}\text { Não foram descritas } \\
\text { recomendações. }\end{array}$ \\
\hline Implementação & $\begin{array}{l}\text { Não foram descritas } \\
\text { recomendações. }\end{array}$ & $\begin{array}{l}\text { Enfatiza a necessidade de } \\
\text { executar pequenas simulações } \\
\text { nos encontros. }\end{array}$ & $\begin{array}{l}\text { Não foram descritas } \\
\text { recomendações. }\end{array}$ \\
\hline Verificação & $\begin{array}{l}\text { Recomenda a realização de } \\
\text { auditoria interna. }\end{array}$ & $\begin{array}{l}\text { Não foram descritas } \\
\text { recomendações. }\end{array}$ & $\begin{array}{l}\text { Destaca que o coordenador } \\
\text { deve realizar a avaliação dos } \\
\text { prazos e de desempenho do } \\
\text { processo. }\end{array}$ \\
\hline Correção & $\begin{array}{l}\text { As ações corretivas devem ser } \\
\text { gerenciadas pelo coordenador } \\
\text { do projeto de implantação, a fim } \\
\text { de garantir que sejam concluídas } \\
\text { antes do início da próxima etapa. }\end{array}$ & $\begin{array}{l}\text { Não foram descritas } \\
\text { recomendações. }\end{array}$ & $\begin{array}{l}\text { O coordenador deve } \\
\text { gerenciar as ações corretivas. }\end{array}$ \\
\hline
\end{tabular}


Quadro 6. Eles já foram incorporados nas diretrizes apresentadas na seção 5 .

A grande maioria das recomendações e comentários dos especialistas foi adicionada nas diretrizes propostas.

Apenas a recomendação de desmembramento maior dos itens do diagnóstico, pelo fato de elas variarem bastante com o tipo de sistema de gestão a ser implantado, tornou-se inviável do jeito como foi sugerido.

\section{Conclusão}

Os sistemas certificáveis de gestão ISO 9001, ISO 14001 e OHSAS 18001 representam um considerável diferencial competitivo para as empresas, pois proporcionam benefícios tanto internos como externos, conforme apresentado na revisão teórica e nas experiências descritas neste artigo.

Contudo, uma das grandes dificuldades apresentadas por vários autores são os altos custos de sua implantação. Nesse contexto, o seu desenvolvimento coletivo e de forma semipresencial pode reduzi-los significativamente (BOUYER; CAMPOS; PONCIANO, 2006; PINTO; CARVALHO; HO, 2006).

O referencial teórico e a apresentação e análise de quatro experiências práticas de implantação coletiva foram utilizadas para dar suporte à sistematização das diretrizes, que, posteriormente, foram validadas por especialistas. Isto permitiu que o objetivo do artigo fosse alcançado.

As diretrizes apresentadas foram formuladas para a implantação de apenas um sistema certificável de gestão por vez, porém sugere-se, no futuro, verificar sua adequação a implantações de sistemas integrados, em que é realizada a implantação de mais de um sistema simultaneamente.

Três fatores são apontados pela literatura como essenciais para o sucesso das diretrizes aqui apresentadas. $\mathrm{O}$ primeiro é o envolvimento e participação da direção; o segundo, o planejamento detalhado de todas as ações; e o terceiro, o treinamento. Projetos que privilegiaram esses elementos, conforme se verificou na literatura, obtiveram melhores resultados.

Este artigo fornece contribuições teóricas relacionadas ao tema "implantação coletiva de sistemas certificáveis de gestão" por meio da elaboração de um referencial teórico, análise de experiências e sistematização de diretrizes.

Sua contribuição aplicada está na disponibilização de orientações que podem ser utilizadas diretamente por grupos de empresas para guiar a implantação de sistemas que tenham por base normas com requisitos certificáveis.
Ressalta-se, como principal limitação deste trabalho, apesar de sua validação por especialistas, a não implantação real das diretrizes da forma exata como estão propostas. Esta é, inclusive, uma sugestão para trabalhos futuros.

\section{Referências}

ARIMURA T.; HIBIKI A.; KATAYAMA H. Is a voluntary approach an effective environmental policy instrument?-A case of environmental management systems. Journal of Environmental Economics and Management, v. 55, p. 281-295, 2008. http://dx.doi.org/10.1016/j. jeem.2007.09.002

BANSAL, P.; BOGNER, W. C. Deciding on ISO 14001: economics, institutions, and context. Long Range Planning v. 35, p. 269-290, 2002. http://dx.doi. org/10.1016/S0024-6301(02)00046-8

BOUYER, G. C.; CAMPOS, E. M.; PONCIANO, W. R. Competência e cultura organizacional: os determinantes de sucesso em sistemas de gestão e estratégia de operações. In: SIMPÓSIO DE ADMINISTRAÇÃO DA PRODUÇÃO, LOGÍSTICA E OPERAÇÕ̃ES INTERNACIONAIS, 9., 2006, São Paulo. Anais... São Paulo: FGV, 2006.

BRANDLER, E.; BRANDLI, L. L. Integração do sistema de gestão ambiental no sistema de gestão de qualidade em uma indústria de confecções. Gestão \& Produção, v. 18, p. 27-40, 2011. http://dx.doi.org/10.1590/ S0104-530X2011000100003

CAMPOS, L. M. S.; MELO, D. A. Indicadores de desempenho dos sistemas de gestão ambiental (SGA): uma pesquisa teórica. Produção, v. 18, n. 3, p. 540-555, 2008. http://dx.doi.org/10.1590/ S0103-65132008000300010

CHAN, E. S. W.; WONG, S. C. K. Motivations for ISO 14001 in the hotel industry. Tourism Management, v. 27, n. 3, p. 481-492, 2006. http://dx.doi.org/10.1016/j. tourman.2004.10.007

CHOUDHRY, R. M.; FANG, D.; MOHAMED, S. The nature of safety culture: a survey of the state-of-the-art. Safety Science, v. 45, n. 10, p. 993-1012, 2007. http:// dx.doi.org/10.1016/j.ssci.2006.09.003

CLOUGHERTY, J. A.; GRAJEK, M. The impact of ISO 9000 diffusion on trade and FDI: A new institutional analysis. Journal of International Business Studies, v. 39, n. 4, p. 613-633, 2008. http://dx.doi.org/10.1057/ palgrave.jibs. 8400368

GAVRONSKI, I.; FERRER, G.; PAIVA, E. L. ISO 14001 Certification in Brazil: motivations and benefits. Journal of Cleaner Production, v. 16, p. 87-94, 2008. http:// dx.doi.org/10.1016/j.jclepro.2006.11.002

GRAEL, P. F. F.; OLIVEIRA, O. J. Sistemas certificáveis de gestão ambiental e da qualidade: práticas para integração em empresas do setor moveleiro. Produção, v. 20, n. 1, p. 30-41, 2010. http://dx.doi.org/10.1590/ S0103-65132010005000017

KIRSCH, M. et al. Quality management in a radiological practice: Experiences with a certification for DIN EN ISO 9001:2000. European Journal of Radiology, 
v. 75, p. e1-e8, 2010. PMid:19447575. http://dx.doi. org/10.1016/j.ejrad.2009.03.059

LANGFORD, D.; ROWLINSON, S.; SAWACHA, E.Safety behaviour and safety management: its influence on the attitudes of workers in the UK construction industry. Engineering, Construction and Architectural Management, v. 7, p. 133-140, 2000. http://dx.doi. org/10.1108/eb021138

LO, C. K. Y.; YEUNG, A. C. L.; CHENG, T. C. E. ISO 9000 and supply chain efficiency: empirical evidence on inventory and account receivable days. International Journal of Production Economics, v. 118, p. 367-374, 2009. http://dx.doi.org/10.1016/j. ijpe.2008.11.010

MILKOVICH, G. T.; BOUDREAU, J. W. Administração de recursos humanos. São Paulo: Atlas, 2000.

MORIONES, A. B. et al. The impact of ISO 9000 and EFQM on the use of flexible work practices. International Journal of Production Economics, v. 130, p. 33-42, 2011. http://dx.doi.org/10.1016/j. ijpe.2010.10.012

NORONHA, D. P.; FERREIRA, S. M. S. P. Revisões da Literatura. In: CAMPELLO, B. S.; CENDÓN, B. V.; KREMER, J. M. Fontes de Informação para Pesquisadores e Profissionais. Belo Horizonte: Ed. UFMG, 2000. p. 191-198.

OLIVEIRA, O. J. Implantação de modelo de gestão para pequenas empresas de projeto de edifícios. Programa de Construção Civil, Escola Politécnica da USP, 2006. Relatório de pós-doutorado.

OLIVEIRA, J. A. et al. Um estudo sobre a utilização de sistemas, programas e ferramentas da qualidade em empresas do interior de São Paulo. Produção, v. 21, n. 4, 2011. http://dx.doi.org/10.1590/ S0103-65132011005000044

OLIVEIRA, M. G. Programa de implantação coletiva de sistema de gestão da qualidade ISO 9001 do SEBRAE Bauru. 2010. Monografia (Pós-Graduação)-Faculdade de Engenharia de Bauru, Universidade Estadual Paulista, Bauru, 2010.

OLIVEIRA, O. J.; OLIVEIRA, A. B.; ALMEIDA, R. A. Gestão da segurança e saúde no trabalho em empresas produtoras de baterias automotivas: um estudo para identificar boas práticas. Produção, v. 20, n. 3, p. 481-490, 2010. http://dx.doi.org/10.1590/ S0103-65132010005000029

OLIVEIRA, O. J.; PINHEIRO, C. R. M. S. Implantação de sistemas de gestão ambiental ISO 14001: uma contribuição da área de gestão de pessoas. Gestão \& Produção, v. 17, n. 1, 2010. http://dx.doi.org/10.1590/ S0104-530X2010000100005

PINTO, S. H. B.; CARVALHO; M. M. HO, L. L. Implementação de programas de qualidade: um survey em empresas de grande porte no Brasil. Gestão \& Produção, v. 13, n. 2, p. 191-203, 2006. http://dx.doi. org/10.1590/S0104-530X2006000200003

PSOMAS E. L. et al. Motives, difficulties and benefits in implementing the ISO 14001 Environmental
Management System”. Management of Environmental Quality, v. 22 p.502-521, 2011. http://dx.doi. org/10.1108/14777831111136090

RISSATTO, I. L. Implantação coletiva de sistema de gestão da qualidade com base na norma ISO 9001:2000. 2008. Monografia (Graduação)-Faculdade de Engenharia de Bauru, Universidade Estadual Paulista, Bauru, 2008.

ROCHA, R. S. Institutional effects on occupational health and safety management systems. Human Factors in Ergonomics and Manufacturing, v. 20, p. 211-225, 2010. http://dx.doi.org/10.1002/hfm.20176

RONDINELLI, D.; VASTAG, G. Panacea, common sense, or just a label? The value of ISO 14001 environmental management systems. European Management Journal, v. 18, v. 5, p. 499-510, 2000.

SHI, H. et al. Barriers to the implementation of cleaner production in Chinese SMEs: government, industry and expert stakeholders' perspectives. Journal of Cleaner Production, v. 16, n. 7, p. 842-852, 2008. http://dx.doi. org/10.1016/j.jclepro.2007.05.002

SILVA FILHO, J. C. G. et al. Aplicação da produção mais limpa em uma empresa como ferramenta de melhoria contínua. Revista Produção, v. 17, n. 1, p. 109-128, 2007. http://dx.doi.org/10.1590/S0103-65132007000100008

SINGH, P. J.; POWER, D.; CHUONG, S. C. A resource dependence theory perspective of ISO 9000 in managing organizational environment. Journal of Operations Management, v. 29, n. 1-2, p. 49-64, 2011. http:// dx.doi.org/10.1016/j.jom.2010.04.002

TEIXEIRA, P. C. Modelo de padronização de processos produtivos em panificadoras. 2010. Monografia (Graduação em Engenharia de Produção)-Faculdade de Engenharia de Bauru, Universidade Estadual Paulista, Bauru, 2010.

TERLAAK, A.; KING, A. A. The effect of certification with the ISO 9000 Quality Management Standard: A signaling approach. Journal of Economic Behavior and Organization, v. 60, p. 579-602, 2006. http:// dx.doi.org/10.1016/j.jebo.2004.09.012

TERZIOVSKI, M.; POWER, D. Increasing ISO 9000 certification benefits: a continuous improvement approach. International Journal of Quality \& Reliability Management, v. 24, n. 2, p. 141-163, 2007. http://dx.doi.org/10.1108/02656710710722266

VINODKUMAR, M. N.; BHASI, M. A study on the impact of management system certification on safety management. Safety Science, v. 49, p. 498-507, 2011. http://dx.doi.org/10.1016/j.ssci.2010.11.009

WAHID, R. A.; CORNER, J.; TAN, P. L. ISO 9000 maintenance in service organizations: tales from two companies. International Journal of Quality \& Reliability Management, v. 28, p. 735-757, 2011. http://dx.doi.org/10.1108/02656711111150823

ZWETSLOOT, G. I. J. M. et al. Safety in a complex world as the result of co-creation and co-learning by key agents. Safety Science Monitor, v. 11, p. 2007, 2007. 